\title{
Histórias em Quadrinhos sobre a pandemia Covid-19 como divulgação científica nas redes sociais da Casa da Descoberta
}

\author{
Comics about the Covid-19 pandemic as scientific dissemination in the social networks of Casa da
}

Descoberta

Cómics sobre la pandemia de Covid-19 como divulgación científica en las redes sociales de la Casa da Descoberta

\begin{abstract}
Resumo
Objetivo: este trabalho busca descrever a utilização de histórias em quadrinhos (HQs) sobre temas relacionados à pandemia Covid-19, como meio de divulgação científica nas redes sociais, facebook e instagram da Casa Descoberta (CD), um centro de divulgação científica da Universidade Federal Fluminense. Metodologia: Inicialmente elaborou-se um questionário diagnóstico para perceber os temas relacionados à Química e Ciência com a pandemia Covid-19 que o público em geral estaria interessado em conhecer. O questionário foi encaminhado em setembro de 2020 via googleform através da rede social. Considerando as respostas de 51 pessoas, elaborou-se $10 \mathrm{HQs}$ animadas que foram publicadas no facebook e instagram da CD de novembro de 2020 a março de 2021. Os temas abordados foram desde álcool gel, materiais de limpeza, sabão e saneantes, sobre Coronavirus, testes para o Covid-19, importância das vacinas, história das pandemias até tipos de vacinas. Para a produção das HQs, primeiramente elaborou-se os storylines e roteiros, até a produção final utilizando o aplicativo Canva ${ }^{\circledR}$, sempre baseados em informações científicas, que foram referenciadas antes dos créditos das HQs. Visando ser um produto atrativo e dinâmico e atendendo às características dos meios de comunicações, as HQS foram animadas para o facebook e na forma de post para o instagram contendo cerca de 10 quadros. Os personagens usados foram as mascotes da CD que dialogavam entre si e diretamente com o público. Resultados: Através dos números de likes, visualizações e compartilhamentos, além dos comentários do público, percebeu-se a importância e interesse das pessoas neste tipo de abordagem e meio de divulgação científicao. Conclusão: foi possível observar que as HQs podem ser um instrumento lúdico e importante de divulgação científica.
\end{abstract}

Palavras-chave: Histórias em quadrinhos; Divulgação científica; Casa da descoberta; Pandemia Covid-19.

\begin{abstract}
Objective: this paper aims to describe the use of comics on themes related to the Covid-19 pandemic, as a means of scientific dissemination on social networks, facebook and instagram, by Casa Descoberta (CD), a scientific dissemination center at the Fluminense Federal University. Methodology: initially a diagnostic questionnaire was elaborated to understand which themes related to Chemistry and Science with the Covid-19 pandemic, that the general public would be interested in knowing. The questionnaire was sent in september 2020 via googleform through the social network. Considering the responses of 51 people, 10 animated comics were created and published periodically on facebook and instagram of CD from November/2020 at mars/2021. The topics covered ranged from alcohol gel, cleaning materials, soap and sanitizers, about Coronavirus, tests for Covid-19, importance of vaccines, history of pandemics until types of vaccines. For the production of the comics, the storylines and scripts were first elaborated, until the final production using the Canva ${ }^{\circledR}$ application, always based on scientific information, which were referenced before the credits of the comics. Aiming to be an attractive and dynamic product and taking into account the characteristics of the means of communication, the comics were animated for facebook and in the form of a post for instagram containing about 10 frames. The characters used were the CD's mascots that dialogued with each other and directly with the audience. Results: through the number of likes, views and shares, in addition to public comments, the importance and interest of people in this type of approach and means of scientific dissemination was perceived.
\end{abstract}


Conclusion: it was possible to observe that comics can be a playful and important instrument of scientific dissemination.

Keywords: Comics; Scientific divulgation; Discovery house; Pandemic Covid-19.

\begin{abstract}
Resumen
Objetivo: este articulo tiene como objetivo describir el uso de cómics sobre temas relacionados con la pandemia Covid-19, como medio de divulgación científica en redes sociales, facebook e instagram en Casa Descoberta (CD), centro de divulgación científica de la Universidad Federal Fluminense. Metodología: inicialmente, se elaboró un cuestionario de diagnóstico para comprender los temas relacionados con la Química y la Ciencia con la pandemia de Covid-19 que el público en general estaría interesado en conocer. El cuestionario se envió en septiembre de 2020 a través de googleform de la red social. Considerando las respuestas de 51 personas, se crearon y publicaron 10 cómics animados en facebook e instagram del CD desde noviembre de 2020 hasta marzo de 2021. Los temas tratados fueron desde gel de alcohol, materiales de limpieza, jabón y desinfectantes, sobre Coronavirus, pruebas para Covid-19, importancia de las vacunas, antecedentes de pandemias e incluso tipos de vacunas. Para la producción de los cómics, primero se elaboraron las historias y guiones, hasta la producción final utilizando la aplicación Canva ${ }^{\circledR}$, siempre en base a información científica, que fueron referenciadas antes de los créditos de los cómics. Con el objetivo de ser un producto atractivo y dinámico y que cumpla con las características de los medios, los comics fueron animados para facebook y en forma de publicación para instagram conteniendo 10 cuadros. Los personajes utilizados fueron las mascotas del CD que dialogaron entre sí y directamente con el público. Resultados: a través de la cantidad de likes, vistas, compartidos y de los comentarios públicos, se notó la importancia e interés de las personas en este tipo de enfoques y medios de divulgación científicao resumo em espanhol. Conclusión: fue posible observar que las historietas pueden ser un recurso lúdico e importante para la divulgación científica.
\end{abstract}

Palabras clave: Cómics; Divulgación cientifica; Casa da descoberta; Pandemia Covid-19.

\title{
1. Introdução
}

A Divulgação Científica (DC) pode ser vista como parte da institucionalização da própria atividade científica e da cultura científica de uma sociedade. É preciso divulgar ciência, por exemplo, por meio da mídia para que a sociedade tenha acesso ao conhecimento e para que ela se torne parte da atividade científica (Vogt \& Polino, 2003; Vogt, 2011; Vogt et al., 2018; Conceição \& Chagas, 2020).

Segundo Bueno (2010), a DC deve ter a preocupação de interagir com as pessoas em geral utilizando-se de instrumentos e processos com o objetivo de levar a informação científica, tecnológica ou afins. Porém, esse compartilhamento de informações deve ser realizado de forma simples, clara e com o conteúdo desejado para que a população entenda o que se quer dizer. Além disso, deve-se preocupar em usar a linguagem daquela cultura para que haja uma boa interação entre os agentes da ação da divulgação científica e aqueles que receberão a informação. Leibruder (2003, p.234), comenta que ao buscar aproximar o público leigo ao tema abordado, os divulgadores científicos procuram utilizar explicações, exemplificações, comparações, metáforas, nomeações, além da própria escolha lexical e um dos meios para isto são os recursos visuais.

A atividade lúdica é um facilitador da aprendizagem das diversas áreas do saber científico ou popular, pois pode despertar a curiosidade e conhecer e possibilita o entendimento de conceitos teóricos e minimizar a distância entre a teoria e a prática de uma forma mais criativa (Moreira, 2011). De Araujo e de Souza (2018) consideram que o lúdico também pode ser entendido como uma linguagem significativa que abre possibilidade ao conhecimento de si, do outro, do mundo e da cultura social, fundamentando-se em um espaço seleto de aprendizagens expressivas. Desse modo, eles defendem a possibilidade do uso das Histórias em Quadrinhos, como uma forma lúdica de abordar assuntos polêmicos que envolvem ciência, tecnologia e sociedade.

Eisner (2005 e 2009) considera que as Histórias em Quadrinhos (HQs) são uma "arte sequencial", isto é, narra uma série de fatos através de quadrinhos. Além disso, as histórias em quadrinhos possuem algumas características que as diferenciam de outros meios de comunicação e mídias visuais, sendo que a principal é a união entre texto e imagem (Vergueiro, 2009, p. 31). 
Brandão (2018, p. 37 - 38) discute em seus trabalhos sobre os estilos e formatos das HQs, que vão desde Tiras (tirinhas); Página dominical, espaço maior do que a tira; Fanzine, que são publicações artesanais e independentes; Revista em Quadrinhos ou gibis; Álbum ou Novela Gráfica (Graphic Novel); Mangá, HQ’s ao estilo japonês; Fotonovelas até Webcomics, que são quadrinhos publicados na internet. Além das webcomics, há autores que denominam as HQ's em meios eletrônicos (internet ou CD-ROM) como Histórias em Quadrinhos Eletrônicas, Digital Comics ou ainda E-Comics, forma mais utilizada nos Estados Unidos. No Brasil, alguns nomes têm sido apresentados, como: HQ Interativa, Quadrinhos Online e HQtrônicas, uma contração de HQ eletrônicas (Evangelista, 2015, p. 23).

Vergueiro (2018, p. 6-12) comenta ainda que as Histórias em Quadrinhos (HQ's) fazem parte na cultura e imaginário de nossa sociedade, especialmente dos jovens, apresenta linguagem simples e atrativa, e é encontrada cotidianamente em vários espaços, meios e atividades, como na publicidade, revistas, em vários livros didáticos, jornais, games, e softwares educativos e até em provas do Exame Nacional do Ensino Médio (Enem).

Além da sala de aula, o uso de HQs no processo de divulgação científica é predominantemente descrito como eficaz, contudo, acreditamos que ainda, como mencionou Vergueiro já em 2004, pesquisas científicas relacionadas ainda são relativamente escassas, muitas vezes devido à ideia de que o emprego dos quadrinhos seria apenas para o público infantil e objeto de uso somente para a melhora na leitura (Vergueiro, 2004).

Leão e Maia (2018) discutem, citando vários autores, a utilização de tirinhas e HQs para o Ensino e Divulgação Científica, dentre outros recursos textuais, pois permitem abordar diversos conteúdos através, por exemplo, da contextualização, cidadania, história da ciência, métodos experimentais e científicos, aos estudantes momentos de reflexão e de compreensão de diversas situações do cotidiano, o que leva a construção de aprendizagens, e por que não dizer, das pessoas em geral. Entretanto, lembramos que Amoreira (2018) menciona que as HQ's estão em um processo de transposição do analógico para o digital, sendo possível encontrá-las em sites, blogs, aplicativos, plataformas de vídeos e nas redes sociais.

Assim, além de ser um recurso importante para o processo de formação e inclusão educacional das pessoas (Campos, 2015; Koutniková, 2017; Xavier, 2017; Bessette, 2020; Carvalho et al., 2021), as HQs são recursos importantes para a alfabetização científica e divulgação de ciências, pois as HQs "falam" às pessoas por meio de uma manifestação artística, extremamente lúdica, composta de imagens articuladas entre si, com ou sem texto" (Caruso \& Silveira, 2009, p.219).

Desde 2020, a Humanidade vive uma pandemia devido ao Covid-19, o que tem de certo modo causado uma mudança nos hábitos das pessoas, principalmente devido ao isolamento preventivo contra a doença. Por outro lado, esta atitude levou as pessoas a usarem de forma mais intensa, seja para suas atividades laborais, educativas, entretenimento e busca de informação sobre a doença e os acontecimentos locais e mundiais, as redes sociais de comunicação, facilitada pelas tecnologias de informação e comunicação (Sampaio, 2020; Guinancio et al, 2020; Pathak, 2021).

Dantas et al (2020) abordam em seu trabalho algumas dessas questões, mas destacou a importância da Divulgação Científica, devido principalmente à proliferação das informações falsas, comumente chamadas de fake news. Neste sentido, os autores lembram da importância da democratização da ciência no combate às informações falsas para disseminar o conhecimento para que as pessoas reflitam sobre o momento vivido e a viver, e para isso, a utilização das redes sociais se torna de suma importância.

[...] Democratizar a ciência e levá-la para toda população pode oportunizar um melhor discernimento daquilo que é importante para que se tenha acesso à saúde, à cidadania e ao engajamento político. Esse é o papel da Divulgação Científica: auxiliar na promoção da Alfabetização Científica e combater a pseudociência por trás das fake news, enfraquecendo as ideias propagadas e, por conseguinte, diluindo o impacto de tendências do "obscurantismo beligerante" que marca a atualidade.

Os Centros e Museus de Ciências configuram-se em espaços onde há um grande potencial para se compreender como 
as revoluções científicas e tecnológicas são processadas e se relacionam com a sociedade, possibilitam discutir com a população sobre a Ciência, nosso passado e as consequências dele para nosso futuro, democratizando assim o conhecimento e permitindo às pessoas que sejam críticas e reflexivas sobre sua importância para a sociedade (Cavalcanti \& Persechini, 2011; Rocha \& Marandino, 2017).

Permitindo a ampliação da visão de mundo e o aumento do gosto pela Ciência por parte dos estudantes, bem como do público em geral, em 2000 foi inaugurado na Universidade Federal Fluminense (UFF) a Casa da Descoberta (CD), um Centro de Divulgação Científica que tem como missão popularizar e divulgar a Ciência através de uma situação de educação não formal. Nesse espaço têm sido expostos experimentos interativos das áreas de Física, Química e Biologia. Além de ser um espaço para a divulgação científica, a CD tem sido ambiente para contribuir com a formação de graduandos de muitas áreas do saber, como por exemplo, Química, Física e Engenharias, uma vez esses alunos atuam como monitores das visitas, o que propicia uma formação mais generalizada ao interagirem com os visitantes, pois devem apresentar e discutir de forma mais simples e lúdica os conteúdos dos aparatos da CD. A CD também tem promovido cursos de atualização de professores, seminários, colóquios científicos, contribuindo com a formação continuada de professores de muitas áreas do conhecimento, bem como, atividades de itinerância para levar a Ciência para o público em geral. Por ser um espaço onde se desenvolvem projetos de pesquisa e extensão, busca-se sempre inovar as estratégias de aproximação com o público, de maneira que se garanta diversão e informação de qualidade para aqueles que o visitam (Borges et al, 2011; Borges et al., 2020).

Ao longo do tempo, foram desenvolvidos mais de 30 experimentos de Química na CD com a intensão de interagir com os sentidos e conhecimentos dos visitantes (Ribeiro et al., 2011; Borges et al., 2020) e servirem para a divulgação científica sobre essa área do saber, assim como, ser um facilitador do processo de ensino-aprendizagem quando da visita de grupos de estudantes e seus professores.

Mais recentemente, a partir de 2020, a Casa da Descoberta passou a utilizar de forma mais intensa suas redes sociais, facebook e instagram, para interagir com seus visitantes e promover a divulgação científica de modo mais abrangente e democrática. Esta ação se deu principalmente motivada pelo momento em que vivemos, uma vez que, devido à pandemia Covid-19 a necessidade de isolamento social, impulsionou ainda mais o uso da internete. Neste sentido, a CD tem publicado posts, vídeos, áudios, além de outros recursos de divulgação científica, bem como, agenciando competições de desenhos sobre diversos temas científicos e sociais em suas redes sociais.

Devido ao nosso interesse no uso de recursos didáticos e metodologias no Ensino de Química (Epifanio et al., 2015; Ribeiro et al., 2015, Fagundes et al., 2016; Silva \& Ribeiro, 2017; Fagundes et al., 2018), além da divulgação científica (Ribeiro et al., 2011; Borges et al., 2011; Borges et al., 2020), decidimos desenvolver histórias em quadrinhos como meio de divulgação científica sobre temas relacionados à pandemia Covid-19, com o objetivo de discutir com a população em geral a importância do conhecimento científico sobre Química e Ciência para a preservação da vida, através de dados científicos e combater as fake news.

\section{Percurso Metodológico}

Podemos classificar este trabalho como uma Pesquisa Qualitativa, pois busca perceber de forma não quantitativa, o quanto as HQs elaboradas podem servir como ferramenta de divulgação científica, através da interação com os visitantes das redes sociais da CD, como o facebook e instagram (Kuark et al., 2010).

Neste sentido, descrevemos a seguir de forma resumida as etapas para a elaboração, aplicação e avaliação de HQs para a divulgação científica de temas e conteúdos sobre a pandemia Covid-19, as quais serão discutidas mais detalhadamente posteriormente.

Etapa 1: Pesquisa de interesse dos visitantes da CD: Neste momento aplicou-se um questionário contendo 9 questões 
durante 13 dias, entre 27 de agosto a 10 de setembro de 2021, para perceber os conteúdos de interesse que o público em geral tinha sobre os temas Química e Ciência na pandemia Covid-19, assim como a respeito da Química no seu cotidiano. Além disto, buscou-se conhecer a faixa etária dos entrevistados e suas localizações residenciais e se conheciam a Casa da Descoberta. O questionário foi elaborado usando a plataforma Google Forms contendo um cabeçalho informando o interesse geral do trabalho, bem como que a participação na pesquisa era de caráter voluntária e anônima. Acreditamos que, pela percepção de interesse dos visitantes em relação aos temas para as HQs nos permitiu compreender melhor qual a necessidade do "saber" dos visitantes da CD, o que nos permitiu uma aproximação à realidade desse público para a elaboração da HQ, pois, segundo Vygotsky se deve valorizar a compreensão das relações, da história, da cultura e da sociedade do educando para a mediação na busca da construção do conhecimento (Bonfim et al., 2019);

Etapa 2: Escolha dos conteúdos das HQs: Baseado nas respostas dos entrevistados foram escolhidos os conteúdos a serem abordados nas HQs a partir dos mais indicados pelos entrevistados;

Etapa 3: Elaboração das HQs: A seguir, elaborou-se uma storyline e roteirização para cada HQ, conforme sugerem as metodologias de produção de HQs (Avelar, 2011). De posse deste material e utilizando a plataforma Canva® produziu-se as $10 \mathrm{HQs}$, que foram finalizadas contendo de 8 a 10 quadros. As linguagens das HQs buscaram ser simples e direta, no formato animado como um vídeo, para o facebook, e na forma de post para o instagram. Estes formatos foram escolhidos em função das possibilidades ligadas aos tipos de redes sociais, uma vez que no facebook é facilitada a inserção de vídeos, enquanto o instagram utiliza fotografias;

Etapa 4: Publicação das HQs: Após a elaboração das HQs nos formatos animados-vídeos e posts, estes produtos de divulgação científica foram publicados nas redes sociais da Casa da Descoberta, isto é, no facebook e instagram, respectivamente. As publicações ocorreram a partir de novembro de 2020 a março de 2021, com um intervalo de cerca de 1 mês entre dezembro e janeiro, dos respectivos anos;

Etapa 5: Avaliação das HQs: Finalmente, através dos likes, compartilhamentos e comentários dos visitantes destas redes sociais, procurou-se perceber o grau de interação e contentamento do público em geral em relação às HQs publicadas.

\section{Resultados e Discussão}

Inicialmente, como já mencionado na metodologia, aplicou-se um questionário com 9 perguntas durante 13 dias, entre 27 de agosto a 10 de setembro de 2021, para perceber os conteúdos de interesse que o público em geral tinha sobre a Química no cotidiano, Química e Ciência na pandemia Covid-19, bem como o perfil dos entrevistados, como a faixa etária e suas localizações (Figura 1). Apesar de ter o tema sobre a Química no cotidiano no questionário, resolvemos elaborar inicialmente as séries de HQS ligadas à pandemia, devido a importância de prestar serviços à sociedade de maneira simples, porém científica, como forma de combater as fake news através do conhecimento sobre os temas de interesse das pessoas, porém, de modo lúdico. 
Research, Society and Development, v. 11, n. 2, e51111225994, 2022

(CC BY 4.0) | ISSN 2525-3409 | DOI: http://dx.doi.org/10.33448/rsd-v11i2.25994

Figura 1. Formulário de percepção de interesse dos visitantes da CD.

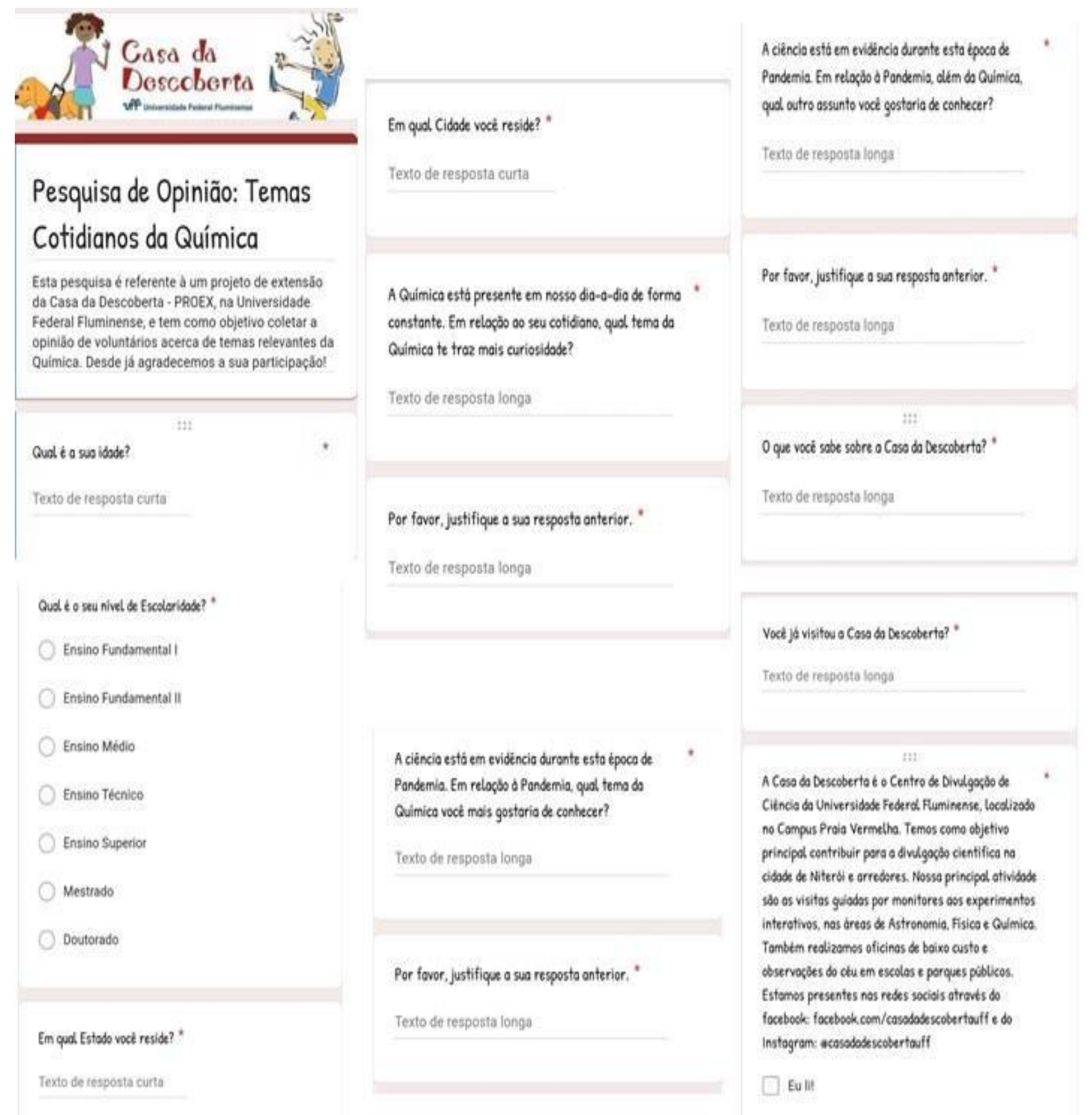

Fonte: Autores.

A Figura 2 mostra os gráficos sobre o perfil dos visitantes que responderam ao Formulário de percepção de interesse dos visitantes da CD obtidos a partir das respostas de 51 entrevistados das perguntas 1 a 4 do formulário. 
Figura 2. Gráficos sobre o perfil dos visitantes que responderam ao Formulário de percepção de interesse dos visitantes da CD.
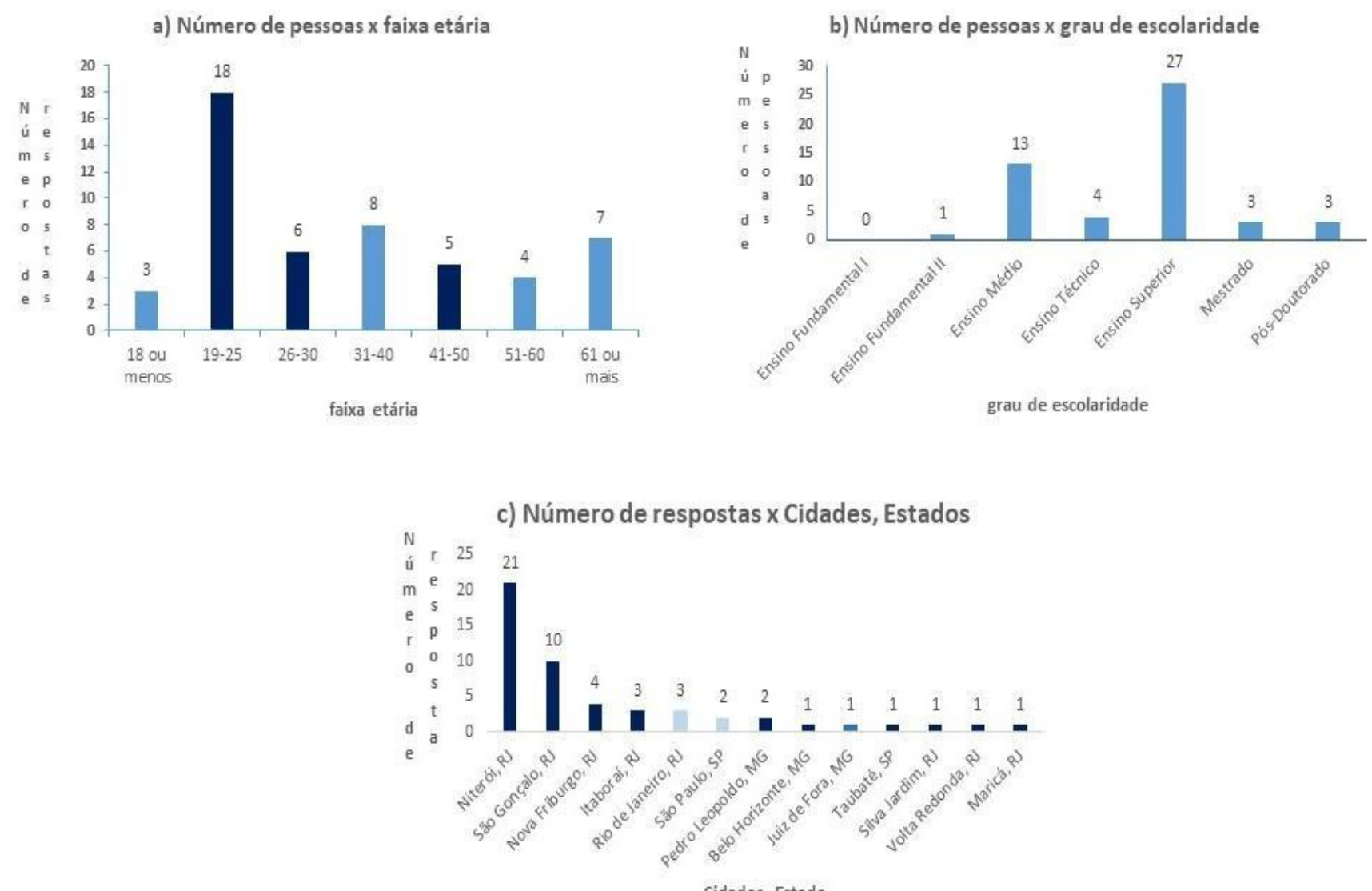

Fonte: Autores.

A partir das respostas da questão número 1, as pessoas das faixas etárias entre 19-25, 31-40 e 61 ou mais anos foram as que mais responderam ao questionário, sendo esse número correspondendo a 18 (35\%), 8 (16\%) e 7 (14\%), respectivamente. Porém, podemos dizer que o universo das pessoas que responderam às perguntas foi diverso, de 11 anos a 77 anos, e considerando as pessoas de até 30 anos e após essa idade representam respectivamente, 27 (53\%) e 24 (47\%), o que reforça a ideia da diversidade das pessoas que responderam ao formulário (Figura 2, item a). Quanto ao grau de escolaridade contida na pergunta 2, aquelas com o nível escolar superior, 33 (65\%) pessoas, representa a maioria, enquanto 17 (33\%) tem grau de Ensino Médio e apenas 1 (2\%) de Ensino Fundamental. Entretanto, percebe-se que o grau é diverso, desde o fundamental ao superior com título de doutor (Figura 2, item b). Por outro lado, como era de se esperar as pessoas residentes em Niterói e região foram as que mais responderam, com um total de 36 (71\%) pessoas (Niterói, São Gonçalo, Itaboraí, Silva Jardim e Maricá), uma vez que se localizam próxima à Casa da Descoberta, assim como, pessoas da capital do Estado, Rio de Janeiro com 3 (6\%). Além destas localidades, residentes em Nova Friburgo 4 (8\%) e Volta Redonda 1 (2\%), cidades localizadas à cerca de $200 \mathrm{Km}$ de distância da CD, e aquelas localizadas nos estados de São Paulo (São Paulo capital e Taubaté) e Minas Gerais (Belo Horizonte, Juiz de Fora e Pedro Leopoldo) também responderam (Figura 2, item c). Esse conjunto de dados foram percebidos a partir das respostas às perguntas 1 a 4, e mostram que apesar do universo total não ser grande, ele é diverso em relação à idade, nível escolar e região próxima à CD.

As perguntas 5, 7 e 9 buscaram saber quais temas relacionados à Química no Cotidiano, a Química na Pandemia e a Ciência na Pandemia, respectivamente, as pessoas gostariam de conhecer um pouco mais. A Figura 3 mostra os gráficos sobre 
os temas preferidos das pessoas que responderam ao questionário.

Figura 3. Gráficos sobre os temas preferidos que responderam ao Formulário de percepção de interesse dos visitantes da CD.
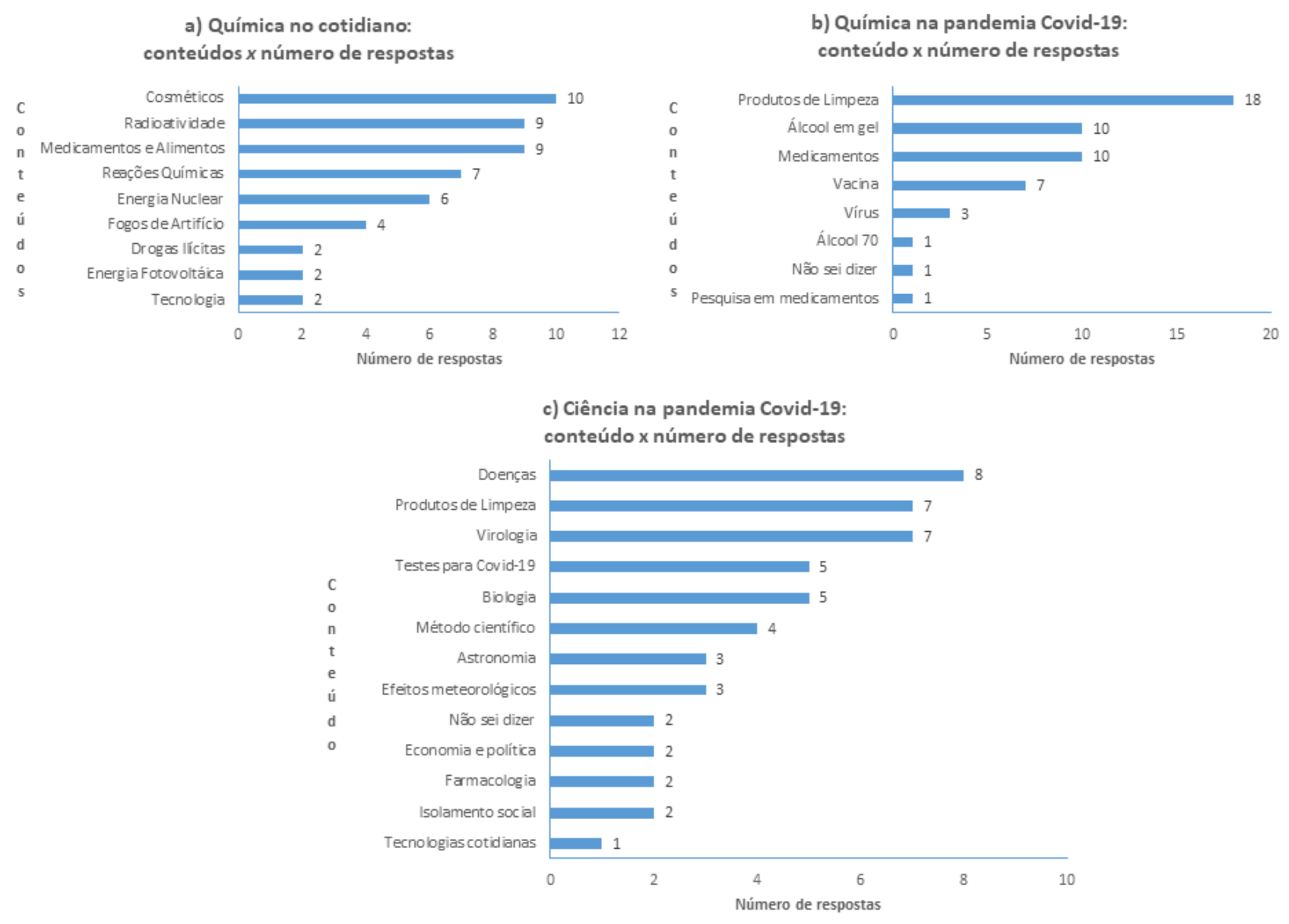

Fonte: Autores.

Os temas relacionados à Química no dia a dia mais citados foram os Cosméticos com 10 (20\%), radioatividade com 9 (18\%) e medicamentos e alimentos com 9 (18\%), além de outros assuntos (Figura 3a). Em relação aos conteúdos e o tema Química na Pandemia Covid-19, as pessoas gostariam de conhecer algo mais sobre produtos de limpeza, álcool em gel, medicamentos e vacinas, uma vez que foram os mais citados com 17 (34\%), 10 (20\%), 10 (20\%) e 7 (14\%) indicações, respectivamente (Figura 3b). Já no tema Ciência na Pandemia (Figura 3c), os conteúdos mais citados foram doenças, produtos de limpeza e virologia, com 8 (16\%), 7 (14\%) e 7 (14\%) das indicações, respectivamente, além de outros conteúdos como, por exemplo, testes para Covid-19 $(5,10 \%)$ e biologia $(5,10 \%)$.

As perguntas 6, 8 e 10 procuraram entender os motivos das escolhas sobre os temas Química no Cotidiano, Química na Pandemia e Ciência na Pandemia, respectivamente. Alguns exemplos estão mostrados na Quadro 1. 
Quadro 1. Temas, conteúdos e justificativas descritos pelos entrevistados.

\begin{tabular}{|c|c|c|}
\hline Tema & Conteúdo & Justificativa \\
\hline \multirow{5}{*}{$\begin{array}{l}\text { Química no } \\
\text { Cotidiano }\end{array}$} & Cosmético & interesse pessoal \\
\hline & Radioatividade & conhecer sobre acidentes \\
\hline & aprimoramento da tecnologia em geral & ligadas ao interesse profissional \\
\hline & reações no cotidiano & entender como as coisas funcionam \\
\hline & $\begin{array}{l}\text { conservantes alimentícios e compostos } \\
\text { farmacêuticos }\end{array}$ & $\begin{array}{l}\text { benefícios e malefícios para a alimentação e novos } \\
\text { princípios ativos à partir de alimentos, plantas e } \\
\text { venenos de animas }\end{array}$ \\
\hline \multirow{5}{*}{$\begin{array}{l}\text { Química } \\
\text { Pandemia }\end{array}$} & Limpeza & interação das substâncias sanitizantes com vírus \\
\hline & produtos de limpeza & quais usar e saber os que fazem mal à saúde \\
\hline & vacinas/meios de prevenção & $\begin{array}{l}\text { informação simples e popular sobre a ciência e } \\
\text { curiosidade no tema }\end{array}$ \\
\hline & Vacinas & descoberta de vacinas \\
\hline & mercado farmacológico & $\begin{array}{l}\text { processo de desenvolvimento de remédios contra } \\
\text { doenças graves na pandemia }\end{array}$ \\
\hline \multirow{5}{*}{$\begin{array}{l}\text { Ciência na } \\
\text { Pandemia }\end{array}$} & pesquisa científica & importância do Ensino de Ciências \\
\hline & doenças que podem causar pandemia & evitar mais riscos \\
\hline & tecnologias no cotidiano & ligadas ao interesse profissional \\
\hline & Limpeza & importância no dia a dia \\
\hline & economia e política & $\begin{array}{l}\text { descaso pela vida e influência da política na } \\
\text { economia }\end{array}$ \\
\hline
\end{tabular}

Fonte: Autores.

De um modo geral, as justificativas pelas escolhas foram curiosidades, busca por maiores informações, conceitos e importância para a sociedade. A partir das justificativas/respostas dos entrevistados, podemos considerar, então, a necessidade das pessoas pelo conhecimento de determinados temas para a melhoria de suas atividades diárias, pessoais e/ou profissionais e seu bem-estar social.

Procurando perceber o que os entrevistados conheciam sobre a Casa da Descoberta, foi perguntado a eles se conheciam a CD (pergunta 11) e se já visitaram a CD (pergunta 12). Através das respostas dos 51 entrevistados, 22 (43\%) disseram que "não sabiam nada sobre a casa, 16 (31\%) pouca coisa e $13(26 \%)$ conheciam a CD. Por outro lado, $42(82 \%)$ pessoas nunca visitaram a Casa da Descoberta, e apenas 9 (18\%) já conhecem o espaço museal. Os dados mostram que a maioria já ouviu falar ou conhecem algo sobre o espaço de divulgação científica, porém, a minoria já a visitou, demonstrando a importância de uma maior divulgação sobre a CD e possíveis parcerias com as Secretarias de Educação dos municípios próximos para uma maior integração com a Sociedade, assim como uma maior utilização das redes sociais pelo centro de divulgação científica. Ressaltamos que para minimizar a questão do desconhecimento sobre a Casa da Descoberta pelos entrevistados, já estava contida no formulário informações sobre a Casa da Descoberta, para estimular que os entrevistados visitem os espaços físicos e virtuais (Figura 1).

Considerando as escolhas dos entrevistados, optamos inicialmente abordar os temas relacionados à pandemia, por ser um interesse de saúde pública importante naquele momento e para que a CD contribuísse de forma contundente na divulgação científica sobre a pandemia Covid-19 e como forma de combate às fakes news, para só futuramente desenvolver HQs sobre a Química e o dia a dia.

Assim sendo, inicialmente preparou-se uma HQ no tema Química na Pandemia, porém, uma vez que os conteúdos sugeridos de certo modo se sobrepuseram entre os dois temas, resolvemos elaborar nove HQs da série Ciência na Pandemia, considerando também a Química na Pandemia. Assim, os conteúdos variaram desde álcool em gel a testes para Covid-19. A Figura 4 mostra as capas de cada HQ produzida, seja para o facebook como para o instagram da CD. 
Figura 4. Capas das 10 HQs produzidas.
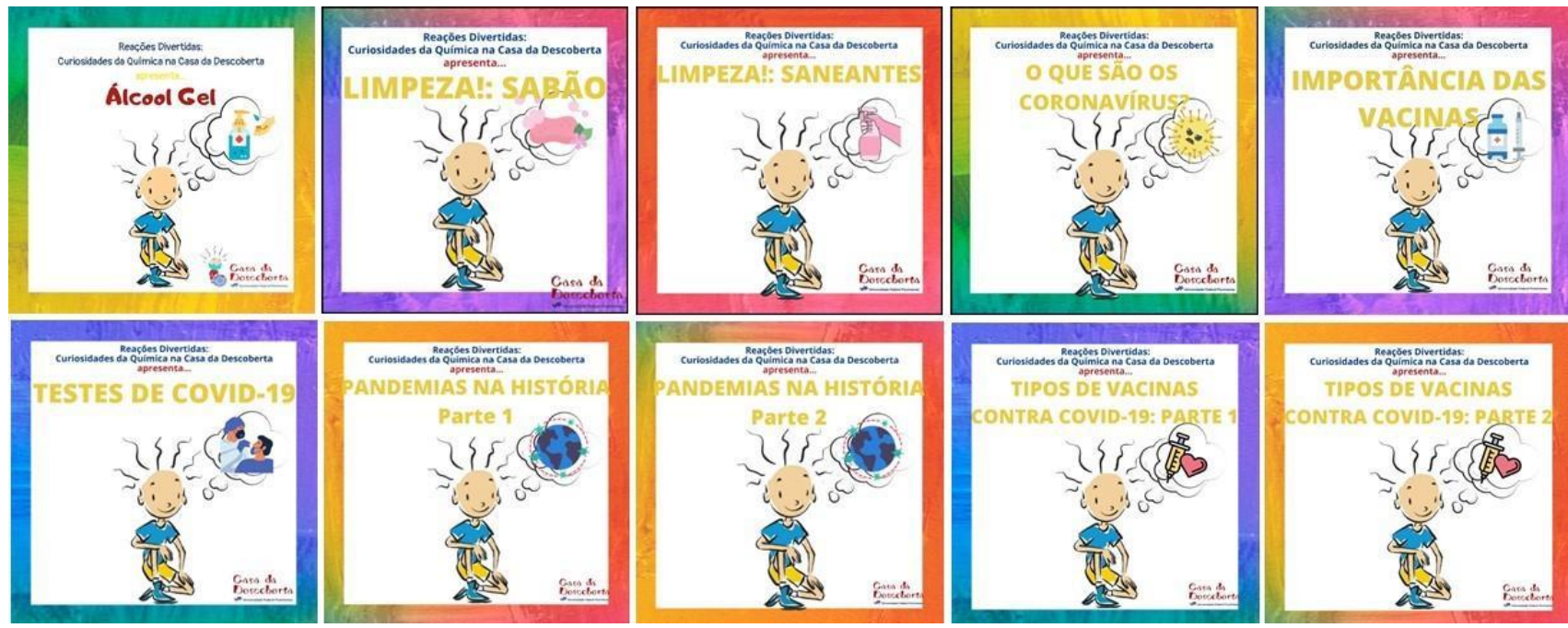

Fonte: Autores.

Nota-se, pela Figura 4, a presença da mascote da CD, assim como os elementos para fornecer uma alusão ao que será tratado, como por exemplo, um frasco de álcool na HQ álcool gel, um desenho de vírus na HQ sobre coronavirus. Além disso, menciona-se o projeto originário deste trabalho, como sendo o apresentador da discussão, bem como o logo da Casa da Descoberta. Lembramos que para a produção final das HQs, preparou-se em um primeiro momento a storyline e argumento, seguidos pela roteirização para cada exemplar.

As publicações das HQs se iniciaram em novembro de 2020, na maioria das vezes às sextas-feiras no período noturno. A cada semana era postada a seguinte, o que ocorreu até o dia 20 de novembro de 2020. As postagens reiniciaram em fevereiro de 2021, e foram finalizadas em março do mesmo ano. O Quadro 2 mostra a sequência das publicações das HQs, assim como os títulos das HQs e os conteúdos abordados em cada exemplar. 
Quadro 2. Datas de publicação, título e conteúdo das HQs produzidas.

\begin{tabular}{|c|c|c|}
\hline $\begin{array}{c}\text { № da HQ e } \\
\text { data de } \\
\text { publicação }\end{array}$ & $\begin{array}{l}\text { Título da HQ animada e HQ-post } \\
\text { [Ferro e Ribeiro, 2020a a 2020f e 2021g a j] }\end{array}$ & Conteúdo geral e específico contido na HQ \\
\hline $\begin{array}{c}1 \\
06 / 11 / 2020\end{array}$ & A Química na Pandemia: Álcool Gel. & \multirow{4}{*}{$\begin{array}{l}\text { Geral: Aborda a importância do uso destes } \\
\text { tipos de produtos para combater a } \\
\text { transmissão do vírus e mostra o modo de } \\
\text { atividade de cada um para a desativação do } \\
\text { organismo. } \\
\text { Específico: substâncias químicas, suas } \\
\text { estruturas e interações }\end{array}$} \\
\hline $\begin{array}{c}2 \\
13 / 11 / 2020\end{array}$ & A Ciência na Pandemia: Limpeza - Sabão. & \\
\hline $\begin{array}{c}3 \\
27 / 11 / 2020\end{array}$ & A Ciência na Pandemia: Limpeza - Saneantes. & \\
\hline $\begin{array}{c}10 \\
20 / 03 / 2021\end{array}$ & A Ciência na Pandemia: Tipos de vacinas: Parte 2. & \\
\hline $\begin{array}{c}4 \\
07 / 11 / 2020\end{array}$ & A Ciência na Pandemia: o que são Coronavírus. & \multirow{3}{*}{$\begin{array}{l}\text { Geral: Discute sobre o que e quais são os } \\
\text { Coronavírus, além de mostrar a } \\
\text { importância de se vacinar e os tipos de } \\
\text { testagem disponíveis. } \\
\text { Específico: classificação dos vírus, ação } \\
\text { das vacinas e sorologia }\end{array}$} \\
\hline $\begin{array}{c}5 \\
15 / 12 / 2020 \\
\end{array}$ & A Ciência na Pandemia: a importância das vacinas. & \\
\hline $\begin{array}{c}6 \\
19 / 12 / 2020\end{array}$ & A Ciência na Pandemia: Testes de Covid-19 & \\
\hline $\begin{array}{c}7 \\
26 / 02 / 2021\end{array}$ & A Ciência na Pandemia: Pandemias na História - Parte 1. & \multirow{2}{*}{$\begin{array}{l}\text { Geral: Faz uma breve abordagem histórica } \\
\text { das pandemias mais importantes, incluindo } \\
\text { a peste negra, varíola, cólera, tuberculose } \\
\text { até o Covid-19 } \\
\text { Específico: contextualiza a história com a } \\
\text { saúde pública e avanço tecnológico }\end{array}$} \\
\hline $\begin{array}{c}8 \\
05 / 03 / 2021\end{array}$ & A Ciência na Pandemia: Pandemias na História - Parte 2. & \\
\hline $\begin{array}{c}9 \\
13 / 03 / 2021\end{array}$ & A Ciência na Pandemia: Tipos de vacinas: Parte 1. & \multirow{2}{*}{$\begin{array}{l}\text { Geral: Comenta sobre os tipos de vacinas e } \\
\text { suas diferenças, além de apresentar alguns } \\
\text { de seus fabricantes. } \\
\text { Específico: Classifica os tipos de } \\
\text { abordagem de elaboração de vacinas e } \\
\text { tecnologias. }\end{array}$} \\
\hline $\begin{array}{c}10 \\
20 / 03 / 2021\end{array}$ & A Ciência na Pandemia: Tipos de vacinas: Parte 2. & \\
\hline
\end{tabular}

Fonte: Autores.

É possível perceber que os temas de interesse escolhidos pelo público, perpassam por conhecimentos importantes para evitar a transmissão do vírus e de simples proteção no dia a dia, como a higiene das mãos e objetos em geral, questões mais específicas sobre vacinas, seus tipos, métodos de testagens e o vírus, assim como, uma contextualização histórica sobre as doenças, desenvolvimento em saúde pública e tecnológica. Essas questões, a nosso ver, demonstram a necessidade deste público em entender procedimentos de proteção simples e mais complexas através de vacinas, compreensão sobre os vírus e como são detectados, além de a necessidade do conhecer sobre como as pandêmicas surgiram durante a história dos povos.

As histórias em quadrinhos foram finalizadas contendo de 8 a 10 quadros para se adequarem às duas redes sociais da $\mathrm{CD}$, o facebook e instagram. No primeiro caso, como é facilitado a inclusão de vídeos, as HQs tiveram um formato animado, isto é, com movimento, mesmo que restrito, visando atingir a sensação de fluidez, além de um fundo musical para dar a sensação de satisfação. As Figuras 5 e 6 mostram a primeira e última HQ publicada, a posição da fonte e créditos. 
Figura 5. A primeira e última HQ produzida.

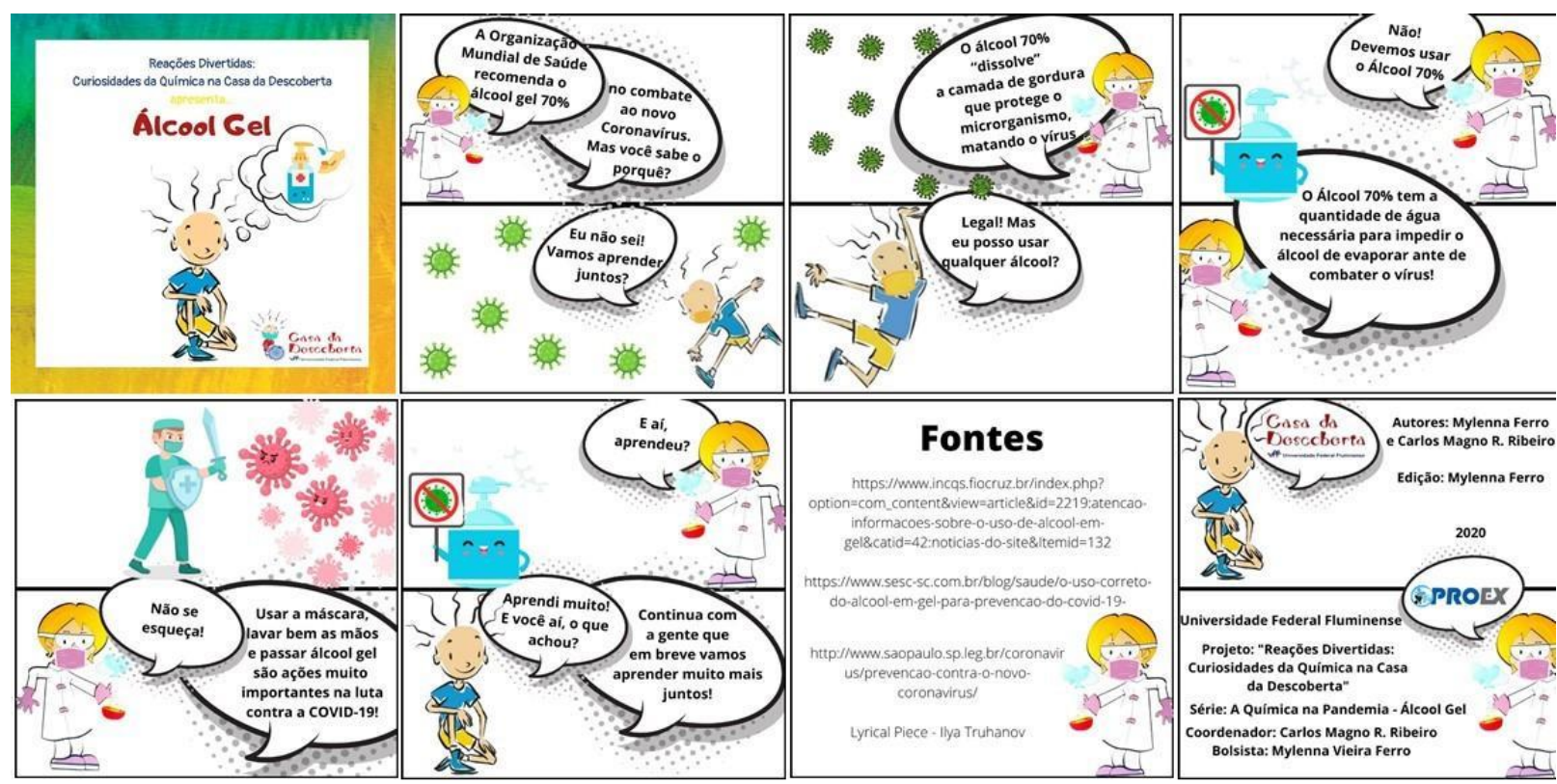

Fonte: Autores.

Figura 6. Décima HQ produzida.

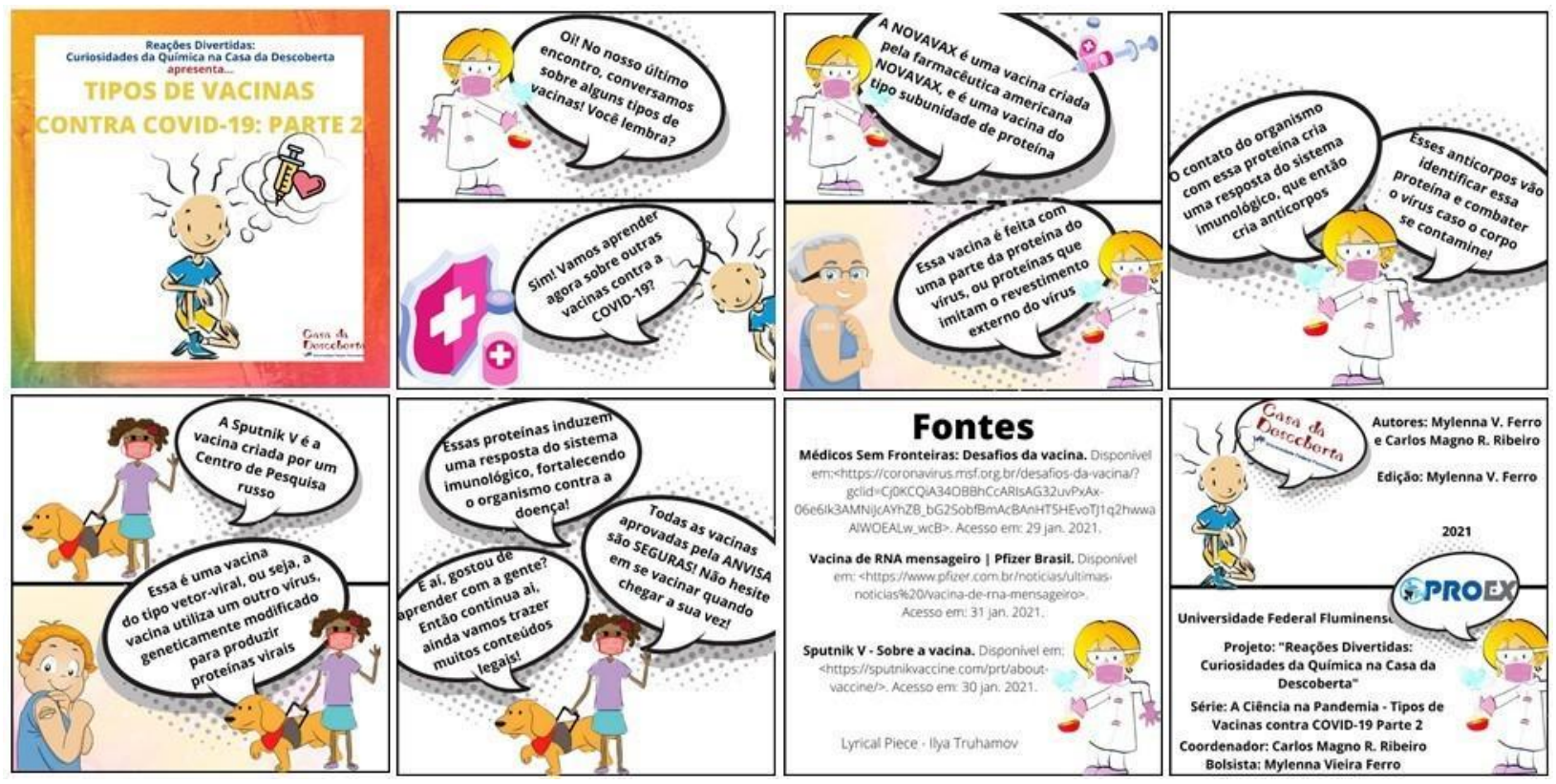

Fonte: Autores.

Todas as HQs apresentam uma capa com o título e a mascote da CD com os elementos característicos ao conteúdo, seguido pelos quadros com o andamento da história proposta, sempre utilizando personagens da CD, que têm uma característica diversa e inclusiva, além da presença de elementos para ilustrar o conteúdo. O penúltimo quadro, apresenta as fontes consultadas no momento da elaboração das HQs, as quais podem ser buscadas pelas pessoas, como forma de demonstrar a importância das fontes e ao combate às fake news, uma vez que as fontes sempre eram relacionadas à Organização Mundial da Saúde, Institutos de Pesquisa brasileiros e internacionais, além de documentos científicos. Na última página aparecem os créditos, procurando demonstrar a importância da autoria e das instituições de origem, além de se buscar, novamente, a importância das fontes. Estas HQs animadas têm um tempo que variaram de 1:000 minutos a 1:00 minutos, dependendo do 
tempo necessário para a leitura dos conteúdos dos balões e informações. Entretanto, lembramos que, caso o seguidor deseje, o vídeo pode ser pausado e reiniciado, o que permite novas leituras ou parar o andamento do vídeo em algum quadro, caso não tenha tido tempo necessário para o entendimento do que estava escrito. No segundo caso, as publicações no Instagram envolvem fotografias. Deste modo, se resolveu construir posts fixos com os quadros das HQs animadas. Neste caso, os quadrinhos podem ser visualizados deslizando-os pela tela do computador ou celular. Este formato por sua vez, permite ao público, utilizar o tempo necessário a ele para a leitura do texto, uma vez que é permitido permanecer lendo no tempo necessário.

A Figura 7, mostra através de um gráfico a evolução mensal da interação dos seguidores e visitantes através das visualizações das postagens no Facebook e Instagram, sendo 1, o primeiro mês de publicação de cada HQ, 9 o nono e 10 o décimo terceiro mês. Lembramos que o último dado referente a cada HQ se refere ao observado em dezembro de 2021, além disso, uma vez que as HQs foram publicadas em semanas diferentes, algumas foram vistas durante treze meses e outras em menor tempo, assim, até o momento, o total de visualizações das 10 HQs foi de 1657 vezes.

Figura 7. Evolução das visualizações das HQs no facebook da CD a cada mês.

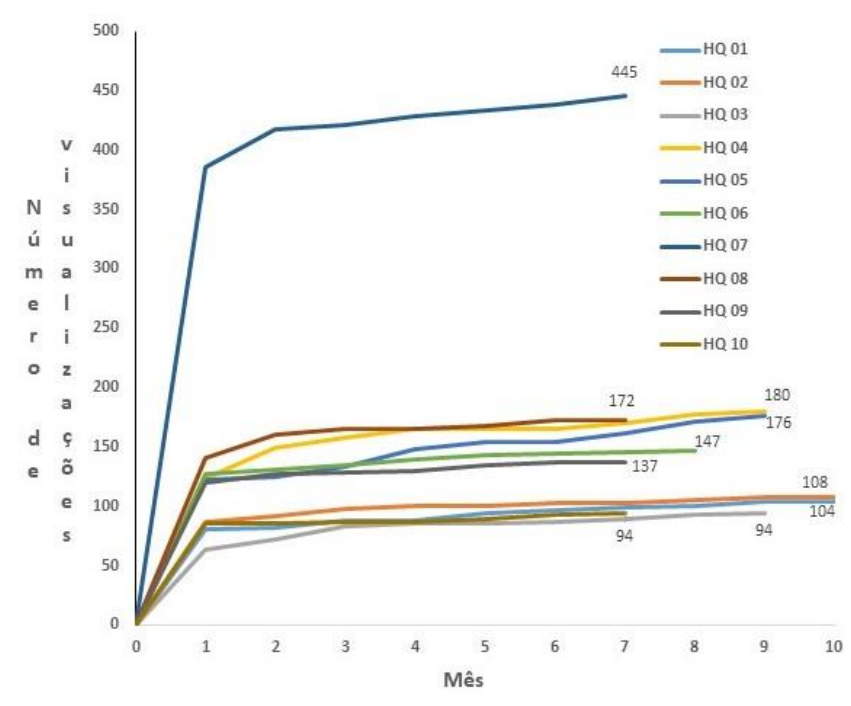

Fonte: Autores.

Além das visualizações, até o momento, as 10 HQs tiveram um total de 159 likes, 20 cometários e 106 compartilhamentos no facebook da CD. Enquanto no Instagram as HQs tiveram 404 likes e 11 comentários.

Através destas interações, podemos dizer que os visitantes e seguidores, de forma esmagadora, gostaram das postagens. Sendo que a sétima HQ, a que trata sobre a pandemia na História-Parte 1, teve a maior interação até o momento, com 438 visualizações no facebook e 60 likes no instagram. Ressaltamos que se trata de uma das postagens da CD mais “curtidas" pelo público. A Figura 8 mostra esta HQ. 
Figura 8. HQ mais vista no facebook da CD.

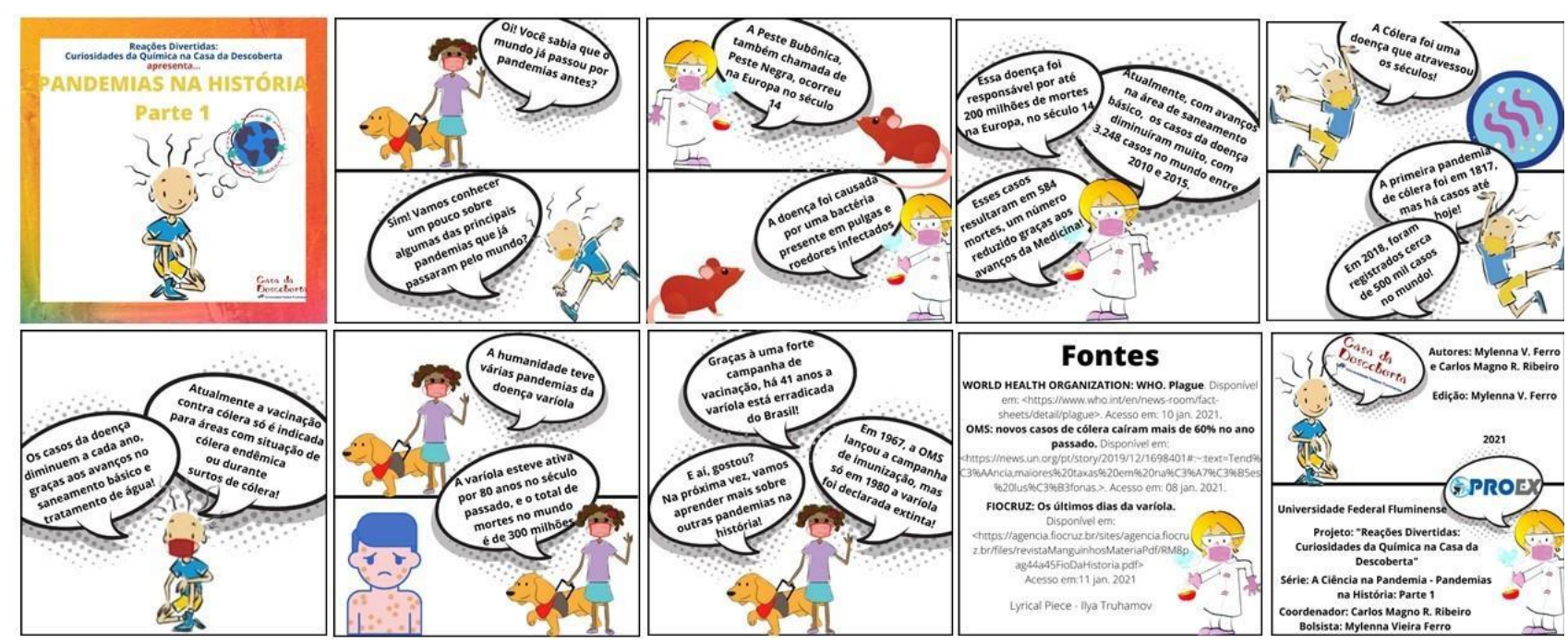

Fonte: Autores.

Nota-se também pela Figura 8, a presença da mascote da CD, assim como os elementos para fornecer uma alusão ao que será tratado, no caso, como por exemplo, os ratos e um desenho de vírus na HQ sobre coronavirus. Além disso do projeto originário deste trabalho, como sendo o apresentador da discussão, bem como o logo da Casa da Descoberta. Ressalta-se o grande interesse dos visitantes em conhecer a História das pandemias, demonstrando a importância do conhecimento do passado para refletirem sobre o presente.

A Figura 9 mostra algumas manifestações e comentários dos visitantes no facebook e instagram da CD em relação a estas $10 \mathrm{Hqs}$ animadas.

Figura 9. Comentários de alguns visitantes nas redes sociais da CD.

\footnotetext{
- Adorei a estória em quadrinhos; - Gostei muito! Mas achei que o tempo que as palavras ficam fixas é pouco para que as crianças de 8 ou 10 anos consigam ler nos 2 balões!! Parabéns; - Muito bom! Parabéns pela iniciativa!; - Estou adorando essas postagens!!!;

- Parabéns pelo belissimo trabalho! Super fã da Casa da Descoberta!;

- Esta, es mas una, muchas otras vendran y espero que los gobernantes futuros esten mejor informados que los actuales, per lo menos em este pais;

-Muito bom o conteúdo!

- Gostei da estória em quadrinhos! Perfeito para os pequenos; - ; -

- Excelente!; -
}

Fonte: Autores.

Percebe-se que os comentários são elogiosos, além de utilizar os emojis da própria plataforma da rede social, demonstrando a satisfação da experiência de ler as postagens dos visitantes. Através do número de likes, visualizações, compartilhamentos e comentários, podemos também dizer que as HQs, sejam na forma animada ou post, são importantes instrumentos interativos de Divulgação Científica da Casa da Descoberta, e porque não dizer da Ciência de um modo geral.

\section{Considerações Finais}

As Hqs quando construídas a partir da manifestação de interesse das pessoas sobre o que ver ou ler, nos aproxima da realidade das importâncias que população tem sobre determinado assunto, fazendo com que a Universidade cumpra com um de seus pilares que é o de compartilhar seu conhecimento através de atividades de Extensão em espaços museais de forma mais 
assertiva. Neste sentido, acreditamos que este trabalho permitiu estabelecer um novo recurso de divulgação científica para a Casa da Descoberta que é dinâmico, simples e participativo.

A Casa da Descoberta se renovou neste momento, ao se emponderar das mídias sociais, recursos de interação social contemporâneo, o que permitiu desenvolver novas linguagens de divulgação científica, na busca da desmistificação e ressignificação da Ciência junto da população. Além de buscar compreender as necessidades da população, como, por exemplo, a discussão de temas relacionados à pandemia Covid-19, um tema presente nos tempos atuais.

Nesse processo de inter e trans aprendizado, ganhamos todos; professores, pesquisadores e alunos da Universidade, na medida que transformam seu conhecimento acadêmico em novas linguagens e os devolvem à sociedade, que também ganha com o processo, o qual permite aos primeiros se reconhecerem como um sujeito coletivo e social, ao mesmo tempo que a sociedade, que ao buscar esse conhecimento pelos mecanismos de Divulgação Científica, permite ressignificar a Ciência ao refletir sobre o que foi visto, possibilitando um desenvolvimento crítico e reflexivo de sua atuação social.

Considerando a importância deste trabalho sobre o uso de HQs na Divulgação Científica, pretende-se desdobrá-lo como metodologia para o processo ensino-aprendizagem, por exemplo, da Química e Divulgação Científica, seja no nível da Educação Básica como no Superior.

\section{Agradecimentos}

Ao Departamento de Química Orgânica e Programa de Pós-Graduação em Ensino de Ciências da UFF. Aos visitantes da Casa da Descoberta.

\section{Referências}

Amoreira, P. (2018). Os Quadrinhos no Contexto Digital: Webcomics, Hqtrônicas e HQs Transmídias. In: Netto, R.; Vergueiro, W. Coleção Quadrinhos na Sala de Aula: estratégias, instrumentos e aplicações. Fortaleza, CE: Fundação Demócrito Rocha.

Araújo, W. A. de, \& Souza, C. F. de. (2018). A utilização das histórias em quadrinhos na perspectiva da ludicidade. In: Sousa, C. F. de, \& Leão, M. F. IF COMICS: Quadrinhos para divulgar a ciência. Uberlândia, Minas Gerais: Edibrás.

Avelar, H. (2011). Quadrinhos: Guia prático. WalPrint Gráfica e Editora, 66p.

Bessette, L. S. (2020). Teaching comics/teaching with comics: A review of with great power comes great pedagogy: Teaching, learning, and comic books. The Comics Grid: Journal of Comics Scholarship, 10(1), 1-5. DOI: https://doi.org/10.16995/cg.190.

Bonfim, V., Solino, A. P., Gehlen, S. T. (2019). Vygotsky na pesquisa em educação em ciências no Brasil: um panorama histórico. Revista Electrónica de Enseñanza de las Ciencias, 18 (1), 224-250. http://reec.uvigo.es/volumenes/volumen18/REEC_18_1_11_ex1452.pdf. Acesso em 31jan 2022.

Borges, M. N., Ribeiro, C. M. R., Araripe, D. R., Chacon, E. P., Coutinho, L. G. R., \& Luz, D. M. (2011). Ações de divulgação de Química na Casa da Descoberta - centro de divulgação de Ciência da Universidade Federal Fluminense. Química Nova, 34(10), $1856-1861$.

Borges, M. N., Chacón, E. P., Ribeiro, C. M. R., Ribeiro, R. P., \& Dantas, L. F. S. (2020). Reflexão, simetria e quiralidade: elaboração de recursos educativos visando a aprendizagem e a divulgação científica. In: Faleiro, W., Nunes, S. M. T., \& Santos, M. P. dos. (Orgs.). Ciências da Natureza na Educação Básica. Goiânia: Kelps, p. 127-145

Brandão, D. (2018) A linguagem dos quadrinhos. In: Netto, R.; Vergueiro, W. Coleção Quadrinhos na Sala de Aula: estratégias, instrumentos e aplicações. Fortaleza, CE: Fundação Demócrito Rocha, p. 33-48.

Bueno, W. C. (2010). Comunicação científica e divulgação científica: Aproximações e rupturas conceituais. Informação \& Informação, 15(1esp), 1. https://doi.org/10.5433/1981-8920.2010v15n1espp1.

Campos, C. R. P. (Org.). (2015). Divulgação científica e ensino de ciências - debates preliminares (Vol. 4). Instituto Federal de Educação, Ciência e Tecnologia do Espírito Santo.

Caruso, F., \& Silveira, C. (2009). Quadrinhos para a cidadania. História, Ciências, Saúde-Manguinhos, 16(1), 217-236. https://doi.org/10.1590/s010459702009000100013.

Carvalho, F., Araujo, C., \& Gonçalves, C. (2021). Divulgação científica e ensino de ciências numa perspectiva inclusiva por meio de histórias em quadrinhos e língua brasileira de sinais - libras. Revista Valore, 6, 706-720. https://revistavalore.emnuvens.com.br/valore/article/view/843.

Cavalcanti, C. C. B., \& Persechini, P. M. (2011). Museus de Ciência e a popularização do conhecimento no Brasil. Field Actions Science Reports. http://journals.openedition.org/factsreports/1085. 
Conceição, V. A. de S., \& Chagas, A. M. (2020). O pesquisador e a divulgação científica em contexto de cibercultura e inteligência artificial. Acta Scientiarum. Education, 42, e52879. https://doi.org/10.4025/actascieduc.v42i1.52879.

Dantas, L. F. S., \& Deccache-Maia, E. (2020). Divulgação científica no combate às fake news em tempos de Covid-19. Research, Society and Development, 9(7). https://doi.org/10.33448/rsd-v9i7.4776.

Eisner, W. (2005). Graphic storytelling and visual narrative. Devir.

Eisner, W. (1999). Comics and sequential art. Martins Fontes.

Evangelista, Eduardo. Quadrinhos digitais: potencializando a leitura. Florianópolis, 2015. Dissertação (Mestrado em Design - Hipermídia Aplicada ao Desig) - Programa de Pós Design da Universidade Federal de Santa Catarina. Florianópolis, 2015. https://repositorio.ufsc.br/handle/123456789/159652.

Fagundes, T. da S. F., Dutra, K. D. B., Ribeiro, C. M. R., Epifanio, R. de A., \& Valverde, A. L. (2016). Using a sequence of experiments with turmeric pigments from food to teach extraction, distillation, and thin-layer chromatography to introductory organic chemistry students. Journal of Chemical Education, 93(2), 326-329. https://doi.org/10.1021/acs.jchemed.5b00138.

Fagundes, T. da S. F., Pacheco, C. M., Martins, P. R. C., Valverde, A. L., \& Ribeiro, C. M. R. (2018). Analysis of foods containing turmeric: A simple experimental sequence to the classroom and scientific divulgation. Revista Virtual de Química, 10(4), 841-850. https://doi.org/10.21577/1984-6835.20180061

Ferro, M. V., \& Ribeiro, C. M. R. [@ casadadescobertauff]. (2020, 6 de novembro). A química na pandemia: Álcool em gel [Vídeo]. Facebook. https://ptbr.facebook.com/casadadescobertauff/videos/1554246431442292.

Ferro, M. V., \& Ribeiro, C. M. R. [@ casadadescobertauff]. (2020, 6 de novembro). A Química na Pandemia: Álcool em Gel [Imagem]. Instagram. https://www.instagram.com/p/CHROVsThJZM/?igshid=19wvmujy6cr1s.

Ferro, M. V., \& Ribeiro, C. M. R. [@ casadadescobertauff]. (2020, 13 de novembro). A ciência na pandemia: Limpeza - Sabão [Vídeo]. Facebook. https://ptbr.facebook.com/casadadescobertauff/videos/3483283495120267.

Ferro, M. V., \& Ribeiro, C. M. R. [@ casadadescobertauff]. (2020, 13 de novembro). A ciência na pandemia: Limpeza - Sabão [Imagem]. Instagram. https://www.instagram.com/p/CIHVOHsBVrB/?igshid=y0vp17bx500k.

Ferro, M. V., \& Ribeiro, C. M. R. [@ casadadescobertauff]. (2020, 27 de novembro). A ciência na pandemia: Limpeza - Saneantes [Vídeo]. Facebook. https://www.facebook.com/watch/?v=496928647925880.

Ferro, M. V., \& Ribeiro, C. M. R. [@ casadadescobertauff]. (2020, 27 de novembro). A ciência na pandemia: Limpeza - Saneantes [Imagem]. Instagram. https://www.instagram.com/p/CH_iNo9BvtI/?igshid=1e10ipgxgsm2p.

Ferro, M. V., \& Ribeiro, C. M. R. [@casadadescobertauff]. (2020, 7 de dezembro). A ciência na pandemia: O que são coronavírus? [Vídeo]. Facebook. https://www.facebook.com/watch/?v=974063336455125.

Ferro, M. V., \& Ribeiro, C. M. R. [@ casadadescobertauff]. (2020, 7 de dezembro). A ciência na pandemia: O que são coronavírus? [Imagem]. Instagram. https://www.instagram.com/p/CIZPoyBBEGn/?igshid=3iyuaftb7jpm.

Ferro, M. V., \& Ribeiro, C. M. R. [@ casadadescobertauff]. (2020, 15 de dezembro). A ciência na pandemia: A importância das vacinas [Vídeo]. Facebook. https://www.facebook.com/watch/?v=142536190975183.

Ferro, M. V., \& Ribeiro, C. M. R. [@ casadadescobertauff]. (2020, 15 de dezembro). A ciência na pandemia: A importância das vacinas [Imagem]. Instagram. https://www.instagram.com/p/CIrZNAXhtT7/?igshid=1io0tqu9h88r5.

Ferro, M. V., \& Ribeiro, C. M. R. [@ casadadescobertauff]. (2020, 19 de dezembro). A ciência na pandemia: Testes de Covid-19 [Vídeo]. Facebook. https://www.facebook.com/watch/?v=827468457820298.

Ferro, M. V., \& Ribeiro, C. M. R. [@ casadadescobertauff]. (2020, 19 de dezembro). A ciência na pandemia: Testes de Covid-19 [Imagem]. Instagram. https://www.instagram.com/p/CI9AMRfBwCT/?igshid=12vpv7oxr3zmp.

Ferro, M. V., \& Ribeiro, C. M. R. [@ casadadescobertauff]. (2021, 26 de fevereiro). A ciência na pandemia: Pandemias na história - parte 1 [Vídeo]. Facebook. https://www.facebook.com/watch/?v=705003530181885.

Ferro, M. V., \& Ribeiro, C. M. R. [@ casadadescobertauff]. (2021, 26 de fevereiro). A ciência na pandemia: Pandemias na história - parte 1 [Imagem]. Instagram. https://www.instagram.com/p/CMD59-dB6VJ/?igshid=skimjjgjlxkp.

Ferro, M. V., \& Ribeiro, C. M. R. [@ casadadescobertauff]. (2021, 05 de março). A ciência na pandemia: Pandemias na história - parte 2 [Vídeo]. Facebook. https://www.facebook.com/watch/?v=916818435740189.

Ferro, M. V., \& Ribeiro, C. M. R. [@ casadadescobertauff]. (2021, 05 de março). A ciência na pandemia: Pandemias na história - parte 2 [Imagem]. Instagram. https://www.instagram.com/p/CMD59-dB6VJ/?igshid=skimjjgjlxkp.

Ferro, M. V., \& Ribeiro, C. M. R. [@ casadadescobertauff]. (2021, 13 de março). A ciência na pandemia: Tipos de vacinas - parte 1 [Vídeo]. Facebook. https://www.facebook.com/watch/?v=549218872725203.

Ferro, M. V., \& Ribeiro, C. M. R. [@ casadadescobertauff]. (2021, 13 de março). A ciência na pandemia: Tipos de vacinas - parte 1 [Imagem]. Instagram. https://www.instagram.com/p/CMWM3FYh8Ds/?igshid=1xjjguwzii317.

Ferro, M. V., \& Ribeiro, C. M. R. [@ casadadescobertauff] (2021, 20 de março). A ciência na pandemia: Tipos de vacinas - parte 2 [Vídeo]. Facebook. https://www.facebook.com/watch/?v=533138498082730. 
Ferro, M. V., \& Ribeiro, C. M. R. [@ casadadescobertauff]. (2021, 20 de março). A ciência na pandemia: Tipos de vacinas - parte 2 [Imagem]. Instagram. https://www.instagram.com/p/CMqXiwSBRyM/?igshid=1ryqedqf3jhdx.

Guinancio, J. C., Sousa, J. G. M. de, Carvalho, B. L. de, Souza, A. B. T. de, Franco, A. de A., Floriano, A. de A., \& Ribeiro, W. A. (2020). COVID - 19: Daily challenges and coping strategies in the face of social isolation. Research, Society and Development, 9(8), e259985474. https://doi.org/10.33448/rsd-v9i8.5474.

Guimarães, E. (1999). Uma caracterização ampla para a história em quadrinhos e seus limites com outras formas de expressão. In Anais, 24 Congresso Brasileiro de Ciências da Comunicação (pp. 1-13). Rio de Janeiro, Universidade Gama Filho.

Kauark, F., Manhães, F. C. \& Medeiros, C. H. (2010). Metodologia da pesquisa: guia prático. Itabuna: Via Litterarum.

Koutníková, M. (2017). The application of comics in science education. Acta Educationis Generalis, 7(3), 88-98. https://doi.org/10.1515/atd-2017-0026.

Leibruder, A. P. (2003). Discurso de divulgação científica. In H. Hathsue Nagamine Brandão (Org.), Gêneros do discurso na escola: Mito, conto, cordel, discurso político, divulgação científica. 4a ed., pp. 229-251. Cortez.

Moreira, M. A. (2011). Aprendizagem significativa: a teoria e textos complementares. Livraria da Física.

Pathak, K. P., Gaire, T., Laya, A.., Neumann, A. P. F. M.., Conti, M. de S. B., Cohrs, F. M., Mello, M. A. F. de ., Mattos, E. B. T. ., \& Ramos, L. R. (2021). Implementations of digital technologies in COVID -19 pandemic and other health threats: multi nationals responses. Research, Society and Development, 10(14), e172101421776. https://doi.org/10.33448/rsd-v10i14.21776.

Ribeiro, C. M. R., Luz, D. M., \& Borges, M. N. (2011). Cadernos de experimentos e curiosidades da Química na Casa da Descoberta. 2a ed., Niterói: EDUFF, v. $1 ., 77 \mathrm{p}$.

Ribeiro, C. M. R., Valverde, A. L., Ribeiro, M. M. J., Souza, T. S. G., Fagundes, T. S. F., Bittencourt, L. B., Dutra, K. D. B., \& Epifanio, R. de A. (2015). "Thin layer chromatography" video lesson and learning motivation in organic chemistry laboratory classes of chemistry, chemical engineering and pharmacy courses - UFF. Revista Virtual de Química, 7(3), 1030-1055. https://doi.org/10.5935/1984-6835.20150056.

Rocha, J. R., \& Marandino, M. (2017). Museus e centros de ciências itinerantes: possibilidades e desafios da divulgação científica. Revista do Encontro de Divulgação de Ciência e Cultura), v. 3. http://revistas.iel.unicamp.br/index.php/edicc/article/view/5220/5968. Acesso em: 27 set. 2021.

Sampaio, R. M. (2020). Teaching and literacy practices in COVID-19 pandemic times. Research, Society and Development, 9(7), e519974430. https://doi.org/10.33448/rsd-v9i7.4430.

Silva, D. d. M., \& Ribeiro, C. M. R. (2017). Analogue three-dimensional memory game for teaching reflection, symmetry, and chirality to high school students. Journal of Chemical Education, 94(9), 1272-1275. https://doi.org/10.1021/acs.jchemed.7b00219.

Souza, C. F., \& Leão, F. M. (Orgs.). (2018). If comics: Quadrinhos para divulgar a ciência. Edibrás.

Rama, A., Vergueiro, W., Vilela T., Ramos, P. \& Barbosa, A. (2004). Como usar as histórias em quadrinhos em sala de aula. São Paulo: Contexto, 160p.

Vergueiro, W. \& Ramos, P. (2009). Quadrinhos na educação: da rejeição à prática. Contexto, 224p.

Vergueiro, W. (2018). As HQs e a Escola. In: Netto, R.; Vergueiro, W. Coleção Quadrinhos na Sala de Aula: estratégias, instrumentos e aplicações. Fortaleza, CE: Fundação Demócrito Rocha, 2018, p. 1-16.

Vogt, C., Gomes, M., \& Muniz, R. (2018). Comciência e divulgação científica. BCCL/Unicamp.

Vogt, C. (2011). The spiral of scientific culture and cultural well-being: Brazil and Ibero-America. Public Understanding of Science, 21(1), 4-16. https://doi.org/10.1177/0963662511420410.

Vogt, C., \& Polino, C. (2003). Percepção pública da ciência: resultados da pesquisa na Argentina, Brasil, Espanha e Uruguai. FAPESP.

Xavier, G. K. R. da S. (2019). Histórias em quadrinhos. Revista Darandina, 1-20. https://doi.org/10.34019/1983-8379.2017.v10.28128. 